\title{
Somogy megye bögölyeinek katalógusa (Diptera: Tabanidae)
}

\author{
MAJER JÓZSEF
}

\begin{abstract}
MAJER J.: Checklist of horseflies of Somogy county (Diptera: Tabanidae)
Abstarct: The species of the Tabanidae family are the so-called horseflies (deerflies, squat flies) with big heads, brilliantly coloured eyes; some females (Chrysops, Tabanus, Haematopota) are livestock pests sucking boold. Many primitive genera feed only from flowers. Larvae live in mud or wet soil and there are either vegetarian (chrysops) or carnivorous (Tabanus, Haematopota). 59 species belong to the Hungarian fauna, among them $43(75 \%)$ were registered in Somogy county, most of them in the Southern part of the region. The horsefly fauna of this county is the best surveyed in Hungary. The Northern part of the county including the representative holiday areas along Lake Balaton should be systematically surveyed, as the Tabanids female are serious blood sucking pest harmful to humans and livestock.
\end{abstract}

\section{Bevezetés}

Az Antarktisz kivételével a Föld valamennyi kontinensén megtalálhatók, az eddig leírt fajok száma meghaladja a 3500-at, ebből Európában 178 él. Magyarországon 10 nemzetségüket és 59 fajukat sikerült kimutatni, további 2 nem előfordulása és 20 faj elôkerülése szinte biztosra vehetô. Somogy megye hazánkban a legszisztematikusabban kikutatott megye bögölyök tekintetében. A felmérésekrôl TóTH (2000) közöl kitûnő összefoglaló elemzést, amibe belefoglalta az adatok tekintélyes részét adó, saját gyửjtéséből származó fenológiai adatokat, továbbá MAJER (1978, 1983, 1985), valamint MAJER \& KRČMAR (1998) bögölyfelmérési eredményeit. Kimutatásában a megyéből összesen 44 bögölyfaj szerepel, ami leírt hazai fajok 75\%-a. A fajok többsége a Dráva mentéról és Belsô-Somogyból származik, míg Külsô-Somogyból csak szórványos adataink vannak.

A régióból leírt fajok száma a további kutatásokkal még akár további 10-zel is emelkedhet.

A bögölyök felmérésének növelését az elôbb említettebbeken kívül, a megye hazánk kiemelt üdülő övezete, a Balaton, valamint a megye jelentős állattenyésztése is indokolja. Ezt az is fontossá teszi, hogy számos Tabanidae faj nöstényének a peteéréshez szüksége van valamilyen melegvérú állat vérére. E szerint 3 alaptípusba sorolhatók: 1. A nőstényeknek a peteérleléshez nincs szükségük állati fehérjére, vért sosem szívnak (autogén, nem vérszívó típus). 2. A nốstények alkalmi vérszívók, de ez nem szükséges a peték érleléséhez és a peterakáshoz(autogén, vérszívó típus). 3. A nőstény csak akkor képes petéket érlelni, ha elózóleg vért szívott, ezek az állat- és humán-egészségügyi szempontból a legveszélyesebbek (anautogén típus). A nőstények nagyobb emlösök (szarvasmarha, sertés, ló, juh, stb.) vagy ember vérét szívják. Mivel szúrásuk fájdalmas, a gazdaállat védekezésére szivásukat többször kénytelenek megsza- 
kítani, míg a szükséges mennyiségú vért megszerzik. Gyakran szívnak friss vagy bomlásnak indult tetemekból is. A nyálukkal együtt begytartalmuk egy részét is a sebbe ürítik. A megszakított és többször megismételt szívásuk kórokozó terjesztô hatásukat csak fokozza. Több mint hetven különféle kórokozót (tularémia, lépfene, járványos vérszegénység, sertéskolera, száj- és körömfájás, stb.) vihetnek át egyik állatról a másikra. A fertőző betegségeknek gyors és nagy területre való elterjesztésében különösen az a tény fokozza a bögölyfajok veszélyességét, hogy jó repülók, és nagy távolságokat is meg tudnak tenni leszállás nélkül. Jelentoos az a fertőzésveszély is, amit úgy idéznek elő, hogy vaskos szívókájukkal viszonylag nagy sebet ejtenek a gazdaállaton, és a szívás befejezése után erre a nyílt sebre más légyfajok tömege gyúlik össze. Petecsomóikat nedves területeken növények leveleire vagy szárára rakják. A kikelt lárvák a vízben vagy a talajban fejlôdnek, többnyire ragadozók. A lárvaállapot 1-2 évig is eltarthat. Bábállapotban 10-24 napot töltenek. Hazánkban kedvezô időjárás esetén - már április végén megjelennek, tömegesen azonban csak június elejétól szeptember közepéig fordulnak elö. A Somogy megyei bögölyfelméréseknek, a fent leírtak miatt a csípószúnyogok felméréséhez hasonlóan a balatoni régióban kiemelt szerepet kell kapniuk.

\section{Somogyból ismert fajok jegyzéke}

\section{Tabanidae}

Atylotus fulvus (Meigen, 1820) - Majer J. 1983. Majer J. \& Krèmar, S. 1998. Tóth S. 2000 .

Atylotus loewianus Villeneuve, 1920 - Majer J. 1983. Majer J. \& Krčmar, S. 1998.

Atylotus rusticus (Linné, 1767) - Majer J. 1983. Majer J. \& Krčmar, S. 1998. Tóth S. 2000.

Chrysops caecutiens (Linnaeus, 1758) - Majer J. 1983. Majer J. \& Kræ̌mar, S. 1998. Tóth S. 2000.

Chrysops flavipes Meigen, I804 - Majer J. 1983. Majer J. \& Krčmar, S. 1998. Tóth S. 2000

Chrysops italicus Zeller, 1842 - Majer J. 1983. Tóth S. 2000.

Chrysops parallelogrammus Zeller, 1842 . Majer J. \& Krěmar, S. 1998. Tóth S. 2000.

Chrysops pictus Meigen, 1820 - Majer J. 1983. Majer J. \& Krčmar, S. 1998.

Chrysops relictus Meigen, 1820 - Majer J. \& Krčmar, S. 1998. Tóth S. 2000.

Chrysops rufipes Meigen, I820 - Majer J. \& Kremar, S. 1998. Tóth S. 2000.

Chrysops viduatus (Fabricius, 1794) - Majer J. 1983. Majer J. \& Krčmar, S. 1998. Tóth S. 2000.

Haematopota crassicomis Wahlberg, 1848 Majer J. 1983.
Haematopota grandis Meigen, 1820 - Tóth S. 2000.

Haematopota italica Meigen, 1804 - Majer J. 1983. Tóth S. 2000.

Haematopota pluvialis (Linnaeus, 1768) Majer J. 1983. Majer J. \& Krčmar, S. 1998. Tóth S. 2000.

Haematopota scutellata (Olsufjev, Moucha \& Chvala, 1964) - Tóth S. 2000.

Haematopota subcylindrica Pandellé, 1883 . Majer J. 1983. Majer J. \& Krčmar, S. 1998. Tóth S. 2000.

Heptatoma pellucens (Fabricius, 1776) Majer J. 1983. Tóth S. 2000.

Hybomitra acuminata (Loew, 1858) - Majer I.

\& Krčmar, S. 1998. Tóth S. 2000.

Hybomitra bimaculata (Macquart, 1826) Majer ). \& Krčmar, S. 1998. Tóth S. 2000.

Hybomitra ciureai (Séguy, 1937) - Majer J. 1983. Majer J. \& Krčmar, S. 1998. Tóth S. 2000

Hybomitra distinguenda (Verall, 1909) - Tóth S. 2000 .

Hybomitra lundbecki Lyneborg, 1959 - Majer J. 1983. Tóth S. 2000.

Hybomitra muehlfeldi (Brauer, 1880) - Majer J. 1983. Majer J. \& Krcmar, S. 1998. Tóth S. 2000.

Hybomitra pilosa (Loew, 1858) - Majer J. \& Krčmar, S. 1998. 


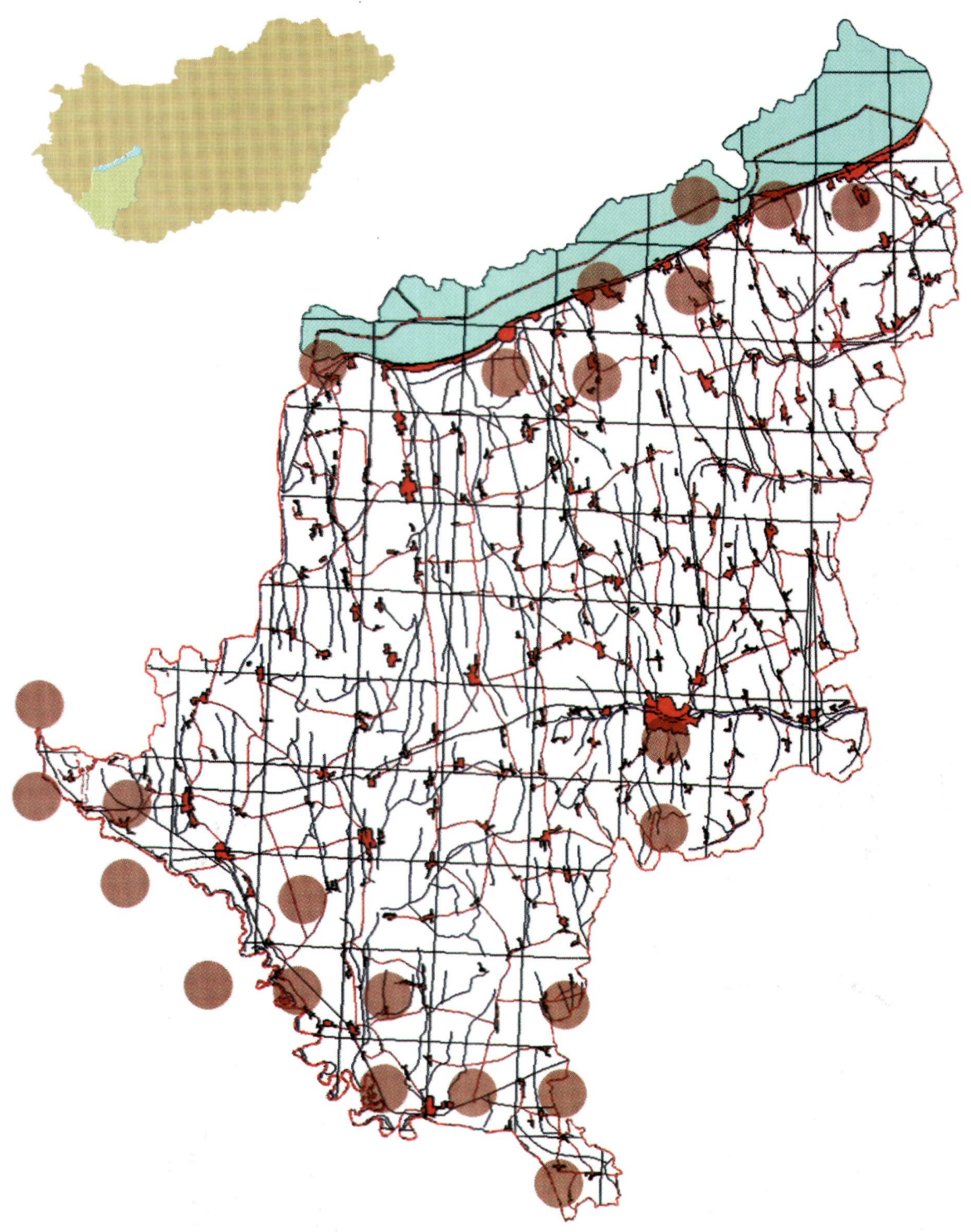

1. ábra: Tabanidae mintavételi helyek Somogy megyében 


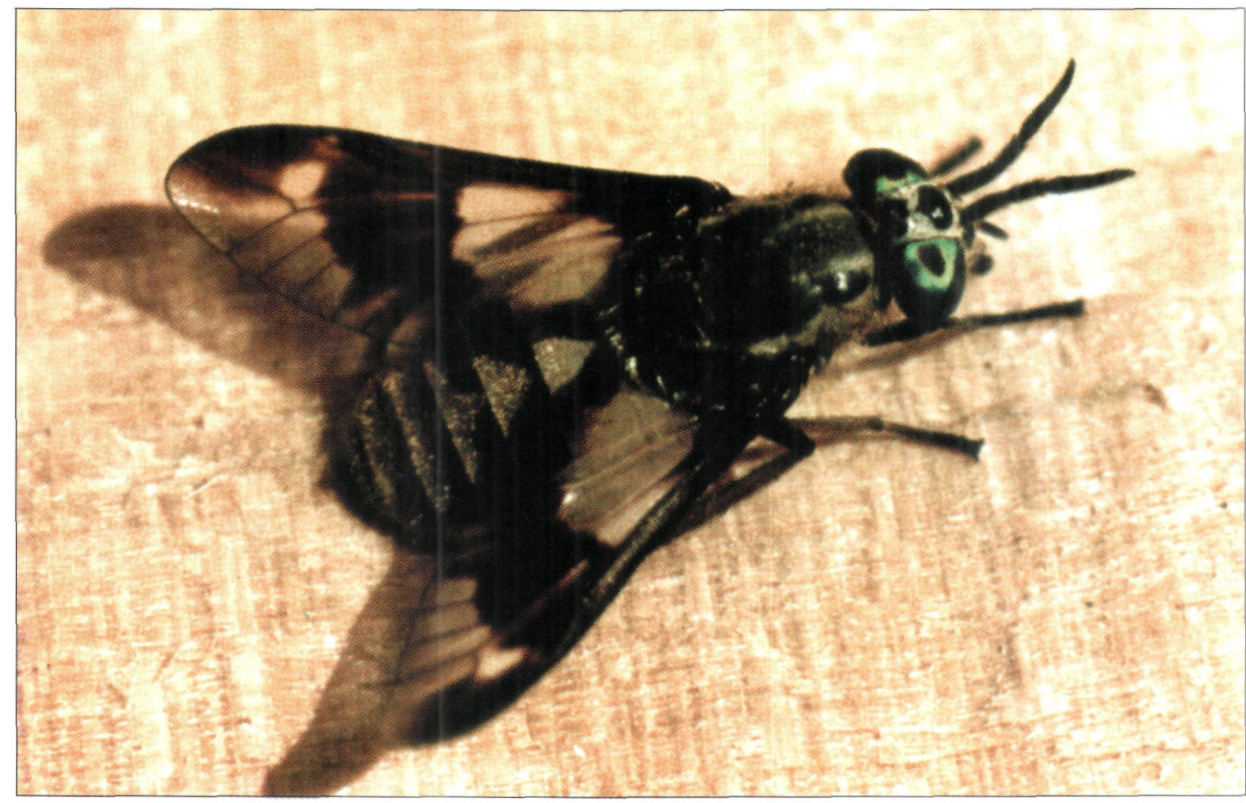

2. ábra: Kétfoltos pôcsik nôstény (Chrysops relictus Meig.) Fotó: Tóth S.

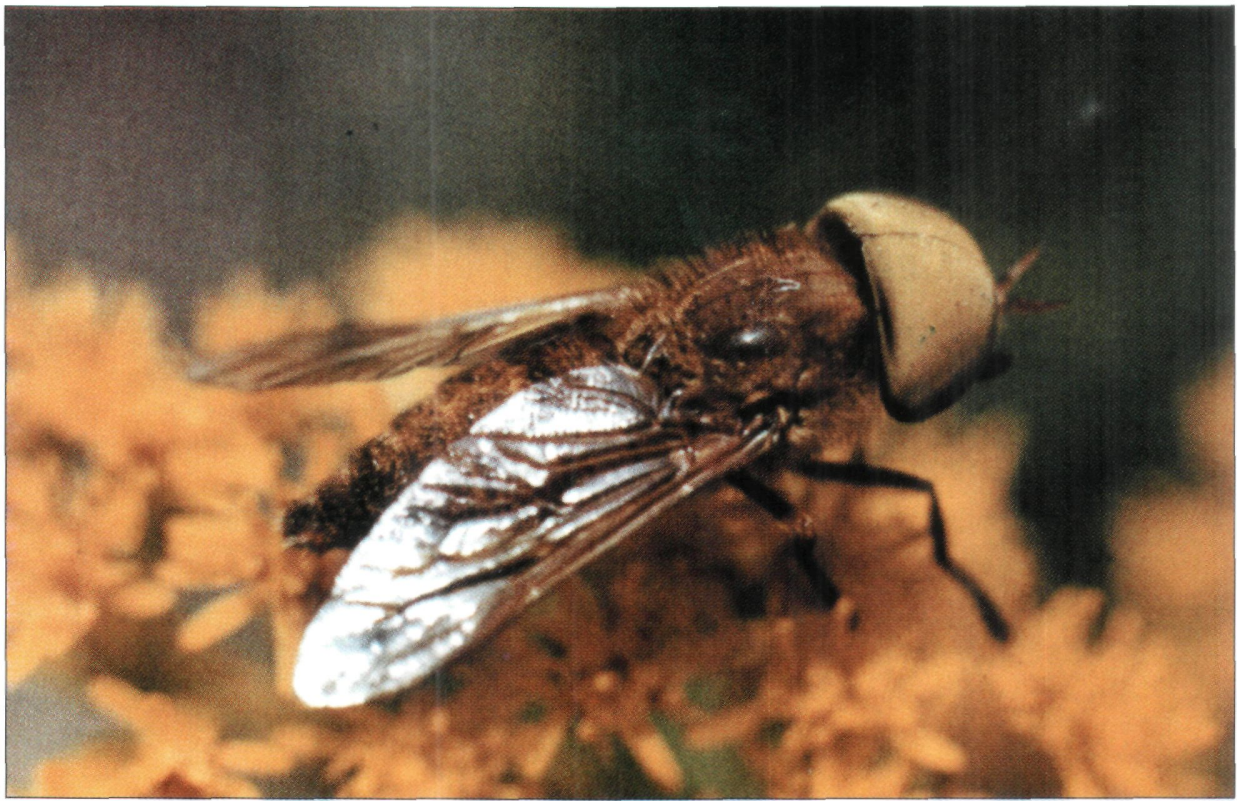

3. ábra: Aranyló bögöly (Atylotus fulvus Meig.) Fotó: Tóth S. 
Hybomitra solstitialis (Meigen, 1820) Majer J. \& Krčmar S. 1998

Hybomitra ucrainica (OIsufjev, 1952) - Majer J.

\& Krčmar, S. 1998 2000 .

Philipomia aprica (Meigen, 1820) - Tóth S.

Tabanus autumnalis Linnacus, 1761 - Majer J. 1983. Majer J. \& Krčmar, S. 1998. Tóth S. 2000 .

Tabanus bovinus Linnaeus, 1758 - Majer J. 1983. Majer J. \& Krèmar, S. 1998. Tóth S. 2000 .

Tabanus bromius Linnaeus, 1758 - Majer J. 1983. Majer J. \& Krčmar, S. 1998. Tóth S. 2000 .

Tabanus cordiger Meigen, 1820 - Majer J. \& Krěmar, S. 1998.

Tabanus exlusus Pandellé, 1883 - Majer J. 1983.

Tabanus glaucopis Meigen, 1820 - Majer J. 1983. Tóth S. 2000.
Tabanus maculicomis Zetterstedt, 1842 . Majer J. 1983. Majer J. \& Krčmar, S. 1998. Tóth S. 2000.

Tabanus miki Brauer, 1880 - Majer J. 1983.

Tabanus quatuornotatus Meigen, 1820 Majer J. 1983.

Tabanus spectabilis Loew, 1858 - Majer J. 1983. Tóth S. 2000.

Tabanus spodopterus Meigen, 1820 - Majer J. 1983. Tóth S. 2000.

Tabanus sudeticus Zeller, 1842 - Majer J. 1983. Majer J. \& Krčmar, S. 1998. Tóth S. 2000.

Tabanus tergestinus Egger, 1859 - Majer J. 1983. Tóth S. 2000. 2000

Tabanus unifasciatus Loew, 1858 - Tóth S.

Therioplectes gigas (Herbst, 1787) - Majer J. 1983. Tóth S. 2000.

\section{1. táblázat: Somogyból ismert fajok száma}

\begin{tabular}{|l|c|}
\hline Rend, Család & Fajszám \\
\hline Diptera & \\
\hline Tabanidae & 43 \\
\hline
\end{tabular}

\section{Irodalom}

Majer, J., 1983. Adatok a Barcsi-borókás Tabaninae (Diptera) faunájához. - Dunántúli Dolgozatok, Term. Tud. Sorozat, 3: 83-88.

MAJER, J., 1985. A magyarországi bögölyök elterjedése, életmódja és gazdasági jelentôsége. Janus Pannonius Tudományegyetem Tanárképzó Karának Tudományos Közleményei, 4: 55-69.

MAJER, J., 1987. Bögölyök-Tabanidae. Akadémiai Kiadó, Bp., XIV. 9. pp. 68.

MAJER, J. \& KRČMAR, S. I998: A Dráva magyar- és horvátországi szakasza ártéri területeinek bögölyfaunájáról (Diptera: Tabanidae). Dunántúli Dolg. Term. tud. Sorozat, 9: 423-430.

Tóth, S. 2000: Adatok a Duna-Dráva Nemzetei Park bögöly faunájához (Diptera: Tabanidae). Somogyi Múzeumok Közl. 14: 331-341. 


\title{
Checklist of horseflies of Somogy county \\ (Diptera: Tabanidae)
}

\author{
JÓZSEF MAJER
}

Family Tabanidae (horseflies, deerflies) is represented by 59 species in the Hungarian fauna, among them 43 (75\%) are known in Somogy county, most of them occuring in the Southern part of the region. Tabanidae fauna of this county is the best surveyed in Hungary. In spite of this fact, the Northern part of the region, including the representative holiday areas along Lake Balaton, the species of deerfly and horsefly fauna are hardly known, This area should be systematically surveyed, as the Tabanids female are serious blood sucking pest harmful to humans and livestock.

\author{
Author's address: \\ Dr. József MAJer \\ Department of General and Applied Ecology \\ University of Pécs \\ H-760l Pécs \\ Ifjúság útja 6 . \\ HUNGARY
}

